\title{
The role of culture in the determination of a standardized or localized marketing strategy
}

\author{
C.H. van Heerden* and C. Barter \\ Department of Marketing and Communication, University of Pretoria \\ Pretoria 0002, Republic of South Africa \\ neels.vanheerden@up.ac.za
}

Received March 2008

\begin{abstract}
Given that culture is an important factor in the international environment, it is a necessity that culture be well understood in order to achieve success in international marketing strategies. Previous research focused more on the broader influence of culture on marketing strategies, with few studies focusing on the way in which culture and marketing affect and are effected by one another, culture's role in the localisation or standardisation of a marketing strategy, as well as which elements of the marketing strategy to standardise versus localise. The sample was drawn from key employees working within reputable multinational organisations in South Africa. No hypotheses were formulated or tested but instead this exploratory study identified areas, which have not been researched in South Africa and eight propositions based on the findings were formulated. The findings indicate that culture plays a very important role in the overall formulation of an international marketing strategy, and it was not conclusive whether such a strategy should be standardised or whether it should be localised. Generally, the responses suggest that a marketer's strategy should suit the local culture in order to reach them and have the desired effect on the target market, and not the other way around because such evolutions could take an extensive amount of time in order to achieve marketing goals.
\end{abstract}

*To whom all correspondence should be addressed.

\section{Introduction}

Following a localised or a standardised marketing strategy in international markets depends on a variety of factors such as culture, politics and economics. With the explosive growth in international trade that has occurred in recent years, dating back to the 1990s (Curry, 1999:21) and with the resultant internationalisation of business, organisations have had to face great learning curves in all areas of their business operations. Culture and cultural distinctions are at the heart of international marketing (Curry, 1999: v), thus it is a necessity that culture be well understood in order to achieve success in international marketing strategies. Before international marketing organisations invest substantial time, effort and resources on cultural education and understanding, they need to be convinced of the significant influence which culture have on marketing and its influence on their target market. Culture has been referred to as the "software of the mind" (Hofstede in Cateora \& Graham, 2007:98), leaving little doubt as to the influence it exerts on various markets and the international marketer's formulation of marketing strategy which does not conflict with the target market's culture.

\section{Literature review}

\section{International marketing}

Hill (2001:25) asserts that the complexity of managing an international business is far greater than domestic business and international organisations need to ensure they have the necessary knowledge and expertise pertaining to international markets that will allow them to exploit the numerous opportunities provided by such markets.

The management of activities across international boundaries is a particularly complex and overwhelming task (Lewin \& Johnson, 1997:136) and expanding marketing and other business operations to international countries infers encountering challenges and problems never before met in the domestic market.

Cateora and Graham (2007:9) describe international marketing as being the performance of business activities designed to plan, price, promote and direct the flow of an organisation's goods and services to consumers or users in more than one location for a profit. A second definition states that international marketing simply refers to an organisation operating in more than one country whose marketing strategy in each can be assumed to have been chosen deliberately (Van Mesdag, 2000:75). This implies that country differences are taken into account when formulating the international marketing strategy.

The distinction between international and global marketing is that global marketers see the world as a single market (Albaum, Strandskov, Dueer \& Dowd, 1992:8) and operate with resolute constancy in that they sell the same thing in the same way everywhere (Buzzell, Quelch \& Bartlett, 1992:11). Global marketing involves the integrated coordination of an organisation's marketing activities throughout the world and pursues global strategies (Bennett 
\& Blythe, 2002:6). This results in global marketing standardisation (Diamantopoulos, Schlegelmilch \& Du Preez, 1995:38).

The first core difference between international and global marketing is that international marketing remains more selective in the choice of country markets versus seeing the entire world as one market and thus targeting all countries. Secondly, the marketing outlooks are vastly different as international marketing recognises the existence of country differences and thus makes room for adaptation and localisation, whereas global marketing does not, and pursues standardisation.

\section{The international marketing environment}

The uniqueness of international marketing emanates from the range of unfamiliar circumstances presented in the environment and the variety of strategies necessary to cope with different levels of uncertainty encountered in foreign markets (Cateora \& Graham, 2007:9). Success will be achieved by those organisations that understand their environment and learn to influence its outcomes (Chee \& Harris, 1993:22). The international marketing environment consists of controllable and uncontrollable factors (Cateora \& Graham, 2007:10-14).

The controllable factors are those that the marketer can manipulate and has direct control over and form the basis of the marketing strategy, including, the marketing mix elements: product, price, distribution (place), and marketing communication (promotion). One of the uncontrollable factors is cultural forces (Cateora \& Graham 2002:8).

\section{Culture}

Culture is pertinent to the study of marketing, especially international marketing (Cateora \& Graham, 2007:94) and in countries with diverse population groups. This means acquiring an understanding and true feeling for the native country's underlying culture, in which marketing is to be conducted. But to do this, marketers need to explore what constitutes culture, as it can often seem to be a highly abstract and complex term.

Culture has been referred to as a system of values and norms that are shared among a group of people that when taken together constitute a design for living. It is also said to be a collective programming of the mind that distinguishes the members of one human group from another. Culture includes systems of values and values are in turn among the building blocks of culture (Hill 2001:79).

For organisations to understand a foreign country's culture it needs to be familiar with its building blocks and once they have this grounding, they are in a far better position to understand culture and its influences on the marketing strategy (Hill, 2001:81). The influence of culture in international marketing is profound (Doole, Lowe \& Phillips, 1994:93). It is believed that culture and cultural distinctions are at the heart of international marketing (Curry 1999: v), thus it is a necessity that culture be well understood in order to achieve success in international marketing ventures. Culture needs to be a major determinant in the establishment of an international marketing strategy, and in order to have culture influence the strategy aptly, there needs to be a real understanding of the different local cultures for each international market being entered.

\section{Standardisation versus cultural adaptation}

The debate around whether marketing efforts should be standardised or adapted to country specifics has not been totally resolved and the banner under which the debate has occurred has evolved from 'standardisation vs. adaptation' to 'globalisation vs. localisation' and again to 'global integration vs. local responsiveness' (Cateora \& Graham, 2007:312).

Advocates of standardisation claim that global market segments are emerging and that marketing efforts not only can, but also should be standardised across markets (Melewar \& Vemmervik, 2004: 863). They believe that the differences across markets and cultures appear to be lessening, and this is reiterated by Herbig (1998:31) who states that there is a converging of all cultures towards one common global culture, and that marketers should endeavour to address global (international) needs, finding areas of commonality and agreement rather than focusing on trivial differences between cultures. They advocate that organisations must learn to operate as if the world was one large market - ignoring superficial country differences (Toyne \& Walters, 1993:422). Their pursuit is also encouraged by the major benefits or advantages from standardisation. Although product standardisation is generally increasing, there are still substantial differences in company practices depending on the products marketed and where they are marketed (Czinkota \& Ronkainen, 2007:328). They further add, "The argument that the world is becoming homogenized may actually be true only for a limited number of products that have universal brand recognition and minimal product knowledge requirements for use".

By using the same marketing strategy the world over, different markets will develop a consistent image of a particular product or brand. A global brand image will avoid the confusion that customers may otherwise face when travelling to different countries and seeing foreign media, if an organisation has local campaigns in each country. Standardisation will result in advantages such as the creation of synergies across markets (Melewar \& Vemmervik, 2004: 863 ) as well as economies of scale, economies of scope and creation of a global brand image (Hill, 2001:544).

Advocates of adaptation, on the other hand, claim that the differences between cultures are so vast that standardisation is not possible and that standardisation results in lost competitive advantage and lower sales (Melewar \& Vemmervik, 2004: 863). This strategy entails that organisations introduce a unique product in each country, with the belief that tastes differ so much between countries that it is necessary to start anew in creating a marketing strategy for each market. Each country should be approached separately as a different market and the 
marketing strategy customised for that particular market (Herbig, 1998:34).

Organisations have the ability to tailor the marketing strategy to suit local markets: and proponents of this philosophy are determined that cultural differences between nations are such that a strategy that works in one nation can fail miserably in another. They believe it is exceptionally difficult to develop a single marketing strategy that would have the desired affects worldwide. Thus, adaptation allows a marketer to take such differences into account and provides the local market with a marketing strategy that appeals to them and will be effective in its function, so creating greater sales and enhancing profits.

By providing a particular international market, such as India, with what they want (e.g. a non-alcoholic beverage), an organisation (such as SA Breweries) can create a distinct competitive advantage for itself because it is receptive to the needs and wants of that market.

The absence of the advantages that emerge from standardisation is in essence the disadvantages of adaptation, and visa versa where the absence of the advantages of adaptation constitutes the very disadvantages of standardisation. Given the reality of significant cultural differences between customer needs and market conditions in international markets and, at the same time, the advantages of more uniform marketing strategies, a debate that focuses on polar extremes does not contribute to a solution (Toyne \& Walters, 1993:423). Viewing the standardisation versus adaptation debate as a black and white issue is not necessarily correct, as there is an important middle ground (Diamantopoulos et al, 1995:38). A grey area exists between the two extremes and it is called "Glocalisation." This follows a philosophy of "think global, act local” (Herbig, 1998:43).

It can be generalised and argued that absolute standardisation is rendered unfeasible as an international marketing strategy and its product -, promotion-, price-, and distribution-related decisions (Baalbaki \& Malhotra, 1993:20) cannot and should not ignore the influence of culture.

\section{Problem statement}

From the previous discussion it is evident that the relationship between an international marketing organisation's marketing strategy and a foreign country's culture is very important. It is imperative that the knowledge base of the international marketer must attest to richness of information based on research in order to attain a comprehensive understanding of its dynamics.

Until recently studies focused on firms located in the United States of America (Theodosiou \& Leonidou, 2003:141). Despite its importance, customer issues, including culture, were least examined by researchers. They further argue that empirical findings strongly indicate that customer issues have a rather significant effect on marketing strategy standardization or adaptation.
A more contemporary view is required and the perceptions of South African branches of multinational corporations will be explored in terms of their experience with the issue of standardisation versus a localised strategy - not only experience gained in South Africa, but perhaps also in other global markets.

\section{Research objectives}

The overarching objective of this study is to explore the possible convergence of global strategy, the way in which culture and marketing affect and are effected by one another, culture's role in the localisation or standardisation of a marketing strategy, as well as which elements of the marketing strategy to standardise versus localise.

No hypotheses will be formulated or tested but instead this exploratory study will identify areas, which need more indepth analysis in South Africa. Propositions will be formulated based on the findings.

\section{Methodology}

The study is exploratory-descriptive in nature to facilitate the identification of the interaction of the pertinent variables (Cooper \& Schindler, 1998:11), namely, culture and international marketing. The aim is not to quantify the relationship between them, but rather to explore and describe such a relationship resulting in rich data. According to Cooper \& Schindler (1998:134), the objectives of exploration may be accomplished with the use of qualitative techniques. A qualitative study can obtain rich, insightful results and allow the researcher to study issues in depth and achieve a wealth of detailed data (Hyde, 2000:84) and to achieve the previously stated objectives; a qualitative approach to the research was implemented (Shaw, 1999:61). The method of data collection was the communication mode where personal interviews were conducted and open ended questions were utilised to ensure that responses were vivid and not restricted to pre-derived suggestions.

\section{Sample}

Given that the researcher sought to explore the influence of culture on the international marketing strategy being standardised or localised, international marketing organisations were selected as the unit of analysis. More specifically, key decision makers with experience and knowledge concerning standardisation or localisation within these organisations were identified as being the subjects most able to provide insight into the research problem.

The research was carried out in two phases: to increase the content validity, the first phase consisted of the identification of key corporate marketing managers from selected multinational corporations who were consulted in an attempt to gain industry perspectives on the points of interest and importance of the research problem. Enquiry was also made so as to establish other possible contemporary issues or dilemmas that the international marketing organisation is currently facing regarding international marketing in the face of contrasting culture, which otherwise may not have been identified during the 
literature review. In the second phase the sampling was done and interviews conducted.

In considering which organisations to use in the sample, it was decided that purposive rather than random sampling would be utilised. In this way, a non-probability sample that conformed to certain criteria (Cooper \& Schindler, 1998:245) would emerge. This was an effective way of selecting case-organisations rich in data pertinent to the research problem (Shaw, 1999:63) and thus enabled the researchers to develop a comprehensive understanding of the impact culture have on the development and implementation of the international marketing strategy. To ensure that participating organisations would have sufficient data about the effects of culture on their marketing strategy, judgement sampling was used (Cooper \& Schindler, 1998:245) and criteria such as that the organisation operates in more than 10 countries and has been in existence for more than 15 years, was used.

This research was concerned with a particular sector of the commercial population, namely, international marketing managers or those in related positions with significant international marketing experience. According to Babbie and Mouton (2001:287), a sampling framework of between five and 25 participants for qualitative research studies in South Africa is recommended. A frugal approach was followed whereby fewer, but insightful multinational corporations were approached to make up the sample group. The sample was drawn from key employees working within reputable multinational organisations, which operate in South Africa: Procter \& Gamble, South African Breweries, Gillette, Revlon, Coca-Cola, Kellogs, Kimberley-Clarke and Nestlé. By selecting respondents from such organisations who are recognised for their successful international marketing efforts, ensured that respondents had the necessary exposure and possessed the required insight to make valid and valuable contributions to the research. Respondents were questioned (using a specific discussion guide) on and asked to respond to various matters of interest as identified in the literature review to ascertain whether the theory is in fact tantamount to the status quo of practical business operations and to gauge whether the necessary degree of importance is given to the topic being researched. They were also required to provide information on their practical and personal experience in the ways in which culture have impacted on and influenced the creation of an international marketing strategy, while being guided with the utilisation of open-ended questions.

\section{Data analysis}

The objective of the research was to arrive at a comprehensive descriptive understanding of the research problem, seeking to emerge with data that was rich, in-depth and narrative - consistent with the qualitative technique of the study. Qualitative enquiry generally adopts an inductive process (Hyde, 2000:82), which was used in this study, and according to Cooper and Schindler (1998:31) induction involves drawing a conclusion from one or more particular facts or pieces of evidence.
The responses of the various interviewees were filtered for key words, and general common threads that may have featured in the suggestions and comments that were offered. Such identification highlighted attitudes that are common to all international marketers and general consensus on an issue was used to create the various categories. The data analysis procedure did not only seek to find similarities, but also looked for variances in responses as this added dimension gave a broad representation of what the research was exploring. Thus where content was found to be unique or different, such differences were not categorised as closely as possible to other responses, but rather kept entirely separate and reported in its exclusiveness. Ensuring that the data analysis did not summarise the data to the extent that it was too similar, but rather keeping it diverse guarded against selective perception of the content.

\section{Results}

Questions were posed to respondents in order to explore:

- $\quad$ the possible convergence of a common world culture;

- $\quad$ the way in which culture and marketing affect and are effected by one another;

- $\quad$ localising marketing strategy;

- $\quad$ the viability of a localised strategy;

- $\quad$ whether culture prohibits standardisation; as well as

- which elements of the marketing strategy to standardise versus localise (adapt).

\section{Common world culture}

The first question related to whether marketers believe that a common world culture is emerging. All respondents feel that there is most definitely a convergence of culture across the globe, but there is not and never will be an absolute eradication of unique and differing cultures, which would ultimately lead to the creation of a common world culture. What the responses point to is the fact that there are more similarities between different cultures than ever before and it is these similarities that may allude to a common world culture emerging. A few verbatim comments highlight the perceptions:

- $\quad$ "There are huge differences but at the end of the day there are a lot of commonalties. I don't believe there is an emerging common world culture but there is a great deal of similarities."

- $\quad$ "There is a high degree of commonality in the basic human truths. What you are getting with the modern world is a convergence of context and of understanding. There is the possibility to leverage more international or culturally unbiased, and culturally neutral methods of communication."

- $\quad$ "We are certainly becoming a global village but I think there is always the stamp of the local culture. I 
think there is a lot more acceptance of different cultures world-wide."

- "There are two parts to this. There is definitely a convergence of a lot more cultures. There is a common world culture - you just have to look at the successful marketing of McDonalds and Coca Cola. Their marketing campaigns are the same around the world and they are getting it right but it's the way they do it. Their execution is not the same and their casting and intrinsic message is fine-tuned. It's the same message but executed differently. You can segment your market and find more common characteristics, but there are niche cultures and if you want to unlock them and grow them, you need to understand them."

- $\quad$ "You can forget about countries having a common culture. I am yet to see one country with one culture. If you look at South Africa, there are plenty of cultures and the same with the United States and the United Kingdom. There are so many sub-cultures within each country you should understand each sub-culture."

It can be surmised that marketers cannot assume homogeneity of cultures across the globe if they cannot even do this on a country by county basis. It is not argued that there are not similarities and congruencies among the cultures within and between countries.

Based on the above finding the following proposition can be formulated:

$\mathrm{P}_{1}$ : There is not an absolute convergence of cultures across the globe to assume homogeneity of cultures.

$\mathrm{P}_{2}$ : $\quad$ Differences in culture between and within countries exist and should be incorporated in developing marketing strategies.

\section{Marketing strategy and culture}

There were two main groups of responses that emerged with regard to whether a marketer should formulate a marketing strategy around a culture or whether a culture would evolve to suit a marketing strategy and product offering.

The first cluster felt that it was not the role of marketing to change culture, but that culture should rather be taken cognisance of and the marketing strategy moulded around this and verbatim statements include:

- “It's better to put culture first and the marketing strategy second."

- $\quad$ "I don't think that people change their culture to suit a product."

- $\quad$ "In most countries the culture dictates the marketing strategy.”

The second group alluded to the possibility that a marketing strategy cannot change the culture per se, but can change consumer attitudes or needs, which in turn are perpetuated through culture. One comment collectively encapsulates this view:

- $\quad$ "Consumer marketing should not be trying to change cultures, but good marketing sometimes has an effect on cultures, for example Levi's. But I don't think they market to change cultures, which is not their intention, it's just that it is such good marketing that it eventually changes culture. The role of marketing should be to adapt to culture but sometimes great marketing will shape culture."

Generally, the responses suggest that a marketer's strategy should suit the local culture in order to reach and have the desired effect on the target market, and not the other way around because such evolutions could take an extensive amount of time in order to achieve marketing goals. But if the strategy brings about change in the process, that favours the marketed product, it should be pursued. If a marketer can create a relatively standardised and cross-cultural strategy that translates across most cultures, then the goals of marketing across countries would be achieved at a minimal spend.

Based on the above observations the following propositions can be suggested:

$\mathrm{P}_{3}$ : A marketing strategy can change the culture of a target market.

$\mathrm{P}_{4}$ : Marketers can create a relatively standardised and cross-cultural strategy that translates across most cultures.

\section{Localising marketing strategy}

The responses were unanimous in terms of whether cultural adaptation and localisation should occur, but the exact extent to which this should occur differed. The responses did not emerge with a precise and absolute answer as to the prescribed extent of local adaptation, as there is no blueprint according to which one should localise any given strategy because this will fluctuate based on the market. Verbatim statements reflect the following:

- “It's critically important but not to the point where you are adapting every element of your marketing campaign or strategy to different markets.

- $\quad$ "It is important that you take culture into account and you adapt to it accordingly."

- " $\quad$ There are a lot of similarities across cultures."

- "One must find synergies by bundling countries together".

Despite the varying degrees of importance attached to the function of localising a marketing strategy and the varying applications thereof, all responses indicated that local adaptation is important in international marketing strategies. Some comments are: 
- $\quad$ "It is very important. We call ourselves globally local. While we are a global organisation we want to be very local in our approach to different markets - it's very important."

- $\quad$ "Cultural adaptation and localisation is extremely important. One cannot use the same commercial and assume it would work everywhere - cultures are different. The same commercial can be offensive in one country and extremely attractive in another."

It seems evident that some degree of localisation of a marketing strategy may be required. However the exact element of the strategy to adapt to local appeals and culture, and to what extent this should be adapted is not finite as this is subject and unique to each market, and all markets are different. The following proposition is proposed:

$\mathrm{P}_{5}$ : Marketers should localise their marketing strategies to a degree.

\section{Viability of a localised strategy}

In trying to establish when a strategy of standardisation versus localisation is followed, respondents mentioned the costs incurred in the process of localisation. It was mentioned that if the gains as a result of localisation were greater than the costs incurred to accrue such gains, then the choice to localise would be a viable one. Comments on this issue are:

- "Differentiate when the value of differentiating outweighs the additional costs, otherwise opt for the lowest cost which is normally standardisation."

- $\quad$ "The strategy may be adapted and localised but it depends on the size of the market. If a market is big enough to justify the cost incurred in adapting, we will."

- $\quad$ "If you had enough money you would always localise but the reality of life is that resources are limited."

- "It depends on the target market. If it's a very homogenous market then standardisation would be a good strategy."

- "When the situation is such that a standardised or international strategy cannot succeed, then you have to go for a local strategy.

It can be deduced that although a more localised strategy would possibly reach the target market and achieve better results, a standardised strategy could achieve relatively good results too, with no additional cost of localisation having been incurred. Thus, if the markets will tolerate and respond to a standardised strategy, marketers should pursue this as it makes economic sense to do so. Marketers should standardise marketing strategy as far as their markets will allow, and once that threshold is reached, localisation needs to be considered.
Based on the above discussion the following proposition is suggested:

$\mathrm{P}_{6}$ : It is more cost effective to customise marketing strategies for local conditions.

\section{Culture prohibits standardisation}

The respondents concurred that culture often requires that the elements of any marketing strategy be modified. Verbatim comments substantiate that culture can prohibit the standardisation of an international marketing strategy.

- "I certainly do think so. I think you will inhibit your business growth prospects if you don't take into account local tastes, preferences and needs. We adopt that strategy world-wide."

- "Yes, given that tastes are so divergent."

- $\quad$ "It does prohibit ultimate standardisation (which is the same advertisement everywhere) but it does not prohibit keeping the same idea."

Although these responses indicate that culture can prohibit standardisation of an international marketing strategy, one does not know the extent to which it prohibits absolute and complete standardisation. The above responses may preclude absolute standardisation, but they do not disqualify partial standardisation.

As the literature study identified, if a global advertisement is localised on for instance, language, localisation has occurred, and such a marketing strategy can no longer be called standardised. International marketers may choose to standardise elements of the strategy, which their various markets will tolerate and be indifferent towards, while localising others that require being altered to reflect local circumstances and culture. Accordingly, culture does not prohibit partial standardisation, but it may prevent absolute standardisation of a marketing strategy. A second category of information that emerged when trying to ascertain whether culture prohibits standardisation of an international marketing strategy is as follows:

- "I think culture does prohibit standardisation of a marketing strategy to a certain extent. I don't think there is anything wrong with standardisation of $a$ marketing strategy across countries that are very similar, but when they are diversified and different, culture certainly does prohibit standardisation."

- "Not entirely. You can standardise certain aspects of the strategy, such as product, and anywhere else synergies are possible because there are cultures with common values."

- $\quad$ "Not necessarily. It depends on the human truths you are going for. There are human truths which rely on worldliness."

Such insight reiterates that culture does not prevent absolute standardisation of a marketing strategy. Again, international 
marketers should standardise where the elements of the marketing strategy do not call for differentiation and modify and localise on those that need alteration to fit into the prevailing culture of the target market. Based on the above the following proposition can be formulated:

$\mathrm{P}_{7}$ : Culture prevents the absolute standardisation of international marketing strategies.

\section{Adaptation of marketing strategy elements}

In the previous section it was intimated that when an international marketer is looking to achieve optimum results through an international marketing strategy, but at the minimum cost, decisions need to be made regarding which elements of the strategy to standardise and which to customise. A summary of the reactions by respondents is:

- "It is determined by the market and needs driven".

- “Consumer needs must be determined and met".

- “Know how you communicate your proposition to your target market”.

- $\quad$ "Communicate the same thing to different people but in a different way".

- "The market determines what degree of standardisation they will tolerate”.

From the above it can be deduced that the marketer must understand what the customer expects, wants and needs. From there, they can access the existing marketing strategy to establish which elements already accommodate and meet the markets' needs and then systematically make the necessary adjustments in instances where the elements of the strategy is simply ill-suited to the market and their culture.

There is not a recipe but as a generalisation, the following responses give an indication which elements of an international marketing strategy marketers feel are best suited to standardisation or customisation.

- "Product is usually the same, price is never standardised, distribution is always local, and promotion is local-even if ever so slightly."

- "I could standardise the product, not price, not distribution (although I could have a strategy that is global best practice, but I would not be able to standardise it), and I certainly could not standardise my promotion and the way I take it to the consumer."

- $\quad$ "I think the core product can be standardised, but packaging can adapt to the culture. The core product is satisfying a need and giving a benefit based on a universal technology, so that could be similar. At the core product level your product can definitely be standardised. Promotion should definitely be customised. Pricing should be $100 \%$ customised. You can't have universal pricing because the economies worldwide are different. Distribution does not call for country customisation, but large groupings of countries, for example developed versus developing countries may do so."

Although the above indicates which of the elements of the strategy should possibly be customised and which could be standardised, it by no means gives any indication of how to go about customising, the reason being that this is highly country and market specific. It is evident that every market will call for different adjustments to be made within any given strategy, and it is for this reason that there are no finite ways to mould marketing strategies to markets.

The following proposition is suggested:

$\mathrm{P}_{8:} \quad$ Price, promotion and distribution strategies are always localised.

\section{Conclusion}

The overarching objective of this study was to explore the possible convergence of world cultures, the way in which culture and marketing affect and are effected by one another, culture's role in the localisation or standardisation of a marketing strategy, as well as which elements of the marketing strategy to standardise versus localise. No hypotheses were formulated or tested but instead this exploratory study identified areas, which have not been researched in South Africa, and eight propositions based on the findings were formulated. -

The findings indicate that culture plays a very important role in the overall formulation of an international marketing strategy, and it was not conclusive whether such a strategy should be standardised or whether it should be localised. Marketers cannot assume homogeneity of cultures across the globe and it is surmised that there are not similarities and congruencies among the cultures within and between countries.

The international marketer needs to study the target market to learn what elements of the strategy might be standardised to allow for economies of scale to be achieved, but at the same time, know which elements to customise so as not to render the entire strategy unsuccessful. It is to be noted that the marketer needs to account for local culture by building it into the marketing strategy, and not expect that the culture will adapt and accept the strategy provided. Generally, the responses suggest that a marketer's strategy should suit the local culture in order to reach them and have the desired effect on the target market, and not the other way around because such evolutions could take an extensive amount of time in order to achieve marketing goals. If a marketer can create a relatively standardised and cross-cultural strategy that translates across most cultures, then the goals of marketing across countries would be achieved at a minimal spend.

It can be deduced that although a more localised strategy would possibly reach the market and achieve better results, a standardised strategy could provide relatively good results too, with no additional cost of localisation having been 
incurred. Marketers should standardise marketing strategy as far as their markets will allow, and once that threshold is reached, localisation needs to be considered.

The responses pointed to the fact that although a certain degree of localisation may be necessary, the approach should be to standardise as far as possible but localise when it is necessary and important for customers. This insight is consistent with Baalbaki and Malhotra (1993:19) who believe that by standardising the marketing effort over similar worldwide segments and differentiating it across dissimilar worldwide segments, the international marketer is able to reap the advantages of both standardisation and customisation.

It seems evident that some degree of localisation of a marketing strategy may be required. However the exact element of the strategy to adapt to local appeals and culture, and to what extent this should be adapted is not finite as this is subject and unique to each market, because markets are different.

\section{References}

Albaum, G., Strandskov, J., Dueer, E. \& Dowd, L. 1992. International marketing and export management. Great Britain: The Bath Press.

Babbie, E. \& Mouton, J. 2001. The practice of social research. Cape Town: Oxford University Press.

Baalbaki, I.B. \& Malhotra, N.K. 1993. 'Marketing management bases for international market segmentation: An alternative look at the standardisation/customisation debate', International Marketing Review, 10(1):19-44.

Bennett, R. \& Blythe, J. 2002. International marketing: Strategy planning, market entry \& implementation. Great Britain: Bell \& Bain Ltd.

Buzzell, R.D., Quelch, J.A. \& Bartlett, C. 1992. Global marketing management. $2^{\text {nd }}$ Edition. United States of America: Addison-Wesley Publishing Organisation.

Cateora, P.R. \& Graham, J.L. 2007. International marketing. $13^{\text {th }}$ Edition. New York: Mcgraw-Hill.

Chee, H. \& Harris, R. 1993. Marketing: A global perspective. London: Pitman Publishing.

Cooper, D.R. \& Schindler, P.S. 1998. Business research methods. $6^{\text {th }}$ Edition. New York: Irwin/Mcgraw-Hill.

Curry, J.E. 1999. International marketing: Approaching and penetrating the international marketplace. California: World Trade Press.

Czinkota, M.R. \& Ronkainen, I.A. 2007. International marketing. Mason, Ohio: Thomson.

Dahringer, L.D. \& Muhlbacher, H. 1991. International marketing: A global perspective. United States of America: Addison-Wesley Publishing Company.
Diamantopoulos, A., Schlegelmilch, B.B. \& Du Preez, J.P. 1995. 'Lessons from Pan-European marketing? The role of customer preferences in fine-tuning the product-market fit'. International Marketing Review, 12(2):38-52.

Doole, I., Lowe, R. \& Phillips, C. 1994. International marketing strategy: Analysis, development and implementation. China: Routledge.

Herbig, P.A. 1998. Handbook of cross-cultural marketing. New York: The Haworth Press.

Hill, C.W.L. 2001. International business: Competing in the global market place. $3^{\text {rd }}$ Edition. New York: Irwin/McgrawHill.

Hyde, K.F. 2000. 'Recognising deductive processes in qualitative reasoning,' Qualitative Market Research: An International Journal, 3(2):82-90.

Lewin, J.E. \& Johnson, W.J. 1997. 'International salesforce management: A relationship perspective', The Journal of Business And Industrial Marketing, 12(3):236-252.

Melewar, T.C. \& Vemmervik, C. 2004. 'International advertising strategy: A review, reassessment and recommendation', Management Decision, 42(7):863-881.

Shaw, E. 1999. 'A guide to the qualitative research process: Evidence from a small organisation study', Qualitative Market Research: An International Journal, 2(2):59-70.

Theodosiou, M. \& Leonidou, L.C. 2003. 'Standardization versus adaptation of international marketing strategy: An integrative assessment of the empirical research', International Business Review, 12:141-171.

Toyne, B. \& Walters, P.G.P. 1993. Global marketing management $-a$ strategic perspective. $2^{\text {nd }}$ Edition. United States of America: Allyn and Bacon.

Van Mesdag, M. 2000. 'Culture-sensitive adaptation or global standardisation - the duration-of-usage hypothesis', International Marketing Review, 17(1):74-84. 